\title{
A Chemo Attractant in Onion Root Exudates Recognized by Ditylenchus dipsaci in Laboratory Bioassay
}

\author{
Y. Spiegel, P. M. Burrows, and M. Bar-Eyal
}

First and third authors: Department of Nematology, Agricultural Research Organization, The Volcani Center, Bet Dagan 50-250, Israel; and second author: Department of Experimental Statistics, Clemson University, Clemson SC 29634. Accepted for publication 26 August 2002.

\begin{abstract}
Spiegel, Y., Burrows, P. M., and Bar-Eyal, M. 2003. A chemo attractant in onion root exudates recognized by Ditylenchus dipsaci in laboratory bioassay. Phytopathology 93:127-132.

A quantitative bioassay that translates preferences of axenically cultured and field population of Ditylenchus dipsaci, observed in vitro, into relative attractiveness of sterile root exudates preparations and their components is described. Onion (Allium cepa cv. White Lisbon) root exudates (ORE) are consistently and significantly much more attractive than the buffer control in all these assays. Exudates from oat cv. Lodi, mustard cv. Albatross and tomato cv. Rehovot 13 are significantly more attractive than the buffer but less attractive than ORE; Arabidopsis sp. cv. Landsberg erecta, oil seed rape cv. Cetes and wheat cv. Bet Hashita are

significant differences in relative attractiveness were detected among exudates from other two cultivars of onion (Texas Grano 502 and Granex Hybrid) and one cultivar of leek (Large American Flag), but exudates from one onion (cv. Evergreen Long White Bunching) and one leek (cv. Broad London) were less attractive than ORE. Relative attractiveness is linear in relation to dilution exponent and therefore log-linear in relation to ORE concentration. Host (onion) penetration study reveals that penetration preferences by $D$. dipsaci follow the same pattern as those predicted by relative attractiveness coefficients estimated in the bioassays. Preliminary characterization of the chemo attractant from ORE, using the behavioral bioassay, demonstrated that it was stable to heat and to proteolytic enzymes, nonvolatile and water soluble with a molecular mass $<700 \mathrm{kDa}$.
\end{abstract} as attractive as the buffer, but canary grass and clover exudates are less attractive than the buffer and, therefore, are classified as repellent. No
Additional keywords: attraction, plant-parasitic nematode, root exudates.
A variety of chemical and physical cues are available to nematodes in their host seeking or food finding behavior (17). The primary mechanisms are believed to involve chemo tactic factors emanating from the host (24). For plant-parasitic nematodes, the major source of such factors is root exudate components $(13,18$, 19). The rare accounts of nematode attraction or repulsion by root exudates were regarded as tentative in a 1980 review (18) because they referred to various general forms of exudates rather than specific components and because of difficulties with comparing different sets of bioassays $(1,7,15,22,23)$. Several responses to specific stimuli from root exudates have been detected since then: (i) attraction and repulsion of Meloidogyne incognita $(6,23)$; (ii) repulsion of $M$. javanica (9); and (iii) aggregation and exploration (stylet thrusting) behaviors in Heterodera schachtii (11).

Moreover, a positive correlation was found between the hypersusceptibility to Heterodera schachtii of two mutants of Arabidopsis thaliana, rhd1-4 and eto3, that overproduce ethylene and their increased ability to attract second-stage juveniles (J2) of H. schachtii (22).

Here we present a quantitative bioassay that translates preferences of axenically cultured Ditylenchus dipsaci, observed in vitro, into relative attractiveness of sterile root exudates preparations and their components.

The genus Ditylenchus contains diverse groups, mycophagous and phytophagous, suggesting multiple and varied adaptations (12). D. dipsaci (Kuhn) Filipjev is polyphytophagous: approximately 500 plant species are known to be its hosts (12). Two races, sometimes sympatric, have been described in Israel (2). The

Corresponding author: Y. Spiegel; E-mail address: spiegely@volcani.agri.gov.il

Publication no. P-2002-1114-02R

(c) 2003 The American Phytopathological Society first race infects canary grass but not onion and garlic, and the second infects onion and garlic but not canary grass. A population of this second race, which causes severe damage to winter-grown onion and garlic crops in Israel, has been used throughout these studies. After reporting relative attractiveness of root exudate preparations from several plant species, and several types of onions and leeks, we describe the preliminary characterization of a specific chemo attractant in root exudates from the onion (Allium cepa cv. White Lisbon).

\section{MATERIALS AND METHODS}

Nematode culture. Unless otherwise mentioned, assays were performed with axenic $D$. dipsaci cultures. Nematodes were propagated aseptically in 5-cm-diameter petri plates containing callus tissue of clover (Trifolium pratense) or onion 'White Lisbon' on a modified Skoog, Tsui, and White nutrient medium (21) with 2,4-dichlorophenoxyacetic acid (2,4-D) at 2 ppm. Parasitic male and female juveniles were dissected from infected plant tissue and washed thoroughly with distilled water before use. Assays P11-P14 were performed with field population of $D$. dipsaci extracted from fresh nematode-infected garlic plants obtained from a nematode-infected field. Parasitic male, female, and juveniles were dissected from infected plant tissue and washed thoroughly with distilled water before use.

Root exudates. A standard preparation of onion root exudates (ORE) was used repeatedly throughout these studies. Seeds of 'White Lisbon' were sterilized in $0.3 \% \mathrm{NaOCl}$ solution for $5 \mathrm{~min}$, washed thoroughly with sterilized distilled water three times and transferred to 9-cm-diameter petri plates containing sterilized distilled water. After 7 or 8 days of incubation in the dark at $17^{\circ} \mathrm{C}$, when approximately $80 \%$ of the seeds had germinated, 66 plantlets (equivalent to $0.2 \mathrm{~g}$ [dry weight] of the original seed) were 
transferred to 5-cm-diameter petri plates with $2.5 \mathrm{ml} 0.05 \mathrm{M} \mathrm{CaCl}_{2}$ solution for further growth in the dark at $17^{\circ} \mathrm{C}$. After 15 days, the root exudates solution was passed through a $0.2-\mu \mathrm{m}$ filter (Schleicher \& Schuell No. FP 030/3, Dassel, Germany) and stored at $4{ }^{\circ} \mathrm{C}$. Root exudates were collected from other plant species in the same manner; this protocol being standardized to the equivalent of $0.2 \mathrm{~g}$ (dry weight) of seed in every case. Included were Arabidopsis sp. (A. thaliana, 'Landsberg erecta'), clover (Trifolium pratense), mustard (Sinapis alba, 'Albatros'), oats (Avena sativa, 'Lodi'), oil seed rape (Brassica napus, 'Cetes'), canary grass (Phalaris paradoxa), tomato (Lycopersicon esculentum, 'Rehovot 13'), wheat (Triticum aestivum, 'Bet Hashita') onion (Allium cepa, 'Granex Hybrid', 'Texas Grano 502' and 'Evergreen Long White Bunching'), and leek (Allium porrum, 'Broad London' and 'Large American Flag').

Bioassays. The basic element consists of a pair-choice test conducted at room temperature $\left(22\right.$ to $\left.25^{\circ} \mathrm{C}\right)$ in a 5 -cm-diameter petri plate containing $1 \mathrm{ml} 1 \%$ agarose in distilled water that was spread into a thin film. Two sources, solutions of exudates or solutions of treated exudates or controls, are spotted on the agar $2 \mathrm{~cm}$ symmetrically from the center on the same diameter, $0.01 \mathrm{ml}$ per target area. A nematode suspension (usually 30 to 50 species) is placed at the center of the plate and covered. Collective mobility of the nematodes is observable through a binocular microscope and counts are always recorded after 30 and $60 \mathrm{~min}$ and sometimes after 120 and $180 \mathrm{~min}$.

One assay consists of several such pairings of sources performed simultaneously with five to seven replicate plates for every pairing. For comparisons of exudates from several plant species, all possible pairings of these source solutions with each other and with ORE (as a positive control) were included. In studies of various treated forms of ORE, it was more common to include only pairings of those treatments with the $0.05 \mathrm{M} \mathrm{CaCl}_{2}$ buffer (as a negative control) or with untreated ORE (as a positive control).

Relative attractiveness. Nematodes are being offered a choice between two sources: their horizontal migration to one of the target areas (presumably up a diffusing gradient), and subsequently their movement around it or remaining stationary at it, is regarded as an expression of preference for the source at that target area over the alternative source at the other target area.

Translation of observed preferences into relative attractiveness coefficients for the sources is based on a model for transitive preferences in pair-choice tests $(5,8)$. Briefly, when source $i$ is paired with source $j$ and the population proportion preferring source $i$ is $p i j=(1-p j i)$, the preference odds-ratio is $l i j=p i j / p j i$. Preference transitivity occurs if the odds-ratios are multiplicative $(l i k=$ lijljk $)$, or equivalently if logarithms of odds-ratios are additive: $\log$ it $(p i k)=\log$ it $(p i j)+\log$ it $(p j k)=(a i-a j)+$ $(a j-a k)=(\mathrm{ai}-\mathrm{ak})$, in which case all pair wise preferences can be explained by the relative attractiveness coefficients $a i$ assigned to sources indexed $i=0,1,2,3, \ldots$ for convenience in notation. One of the $a i$ parameters is arbitrary: we set a $0=$ zero for the control.

This model is fitted by maximum likelihood to the sample pairs of counts $n i$ and $n j$, of just active nematodes reaching spots of sources $i$ and $j$ respectively, recorded at any one time in replicates of all source pairings included. In practice, $(n i+n j)$ accounts for virtually all of the nematodes when the pairing of sources $i$ and $j$ includes at least one highly attractive source. But as few as $10 \%$ of the nematodes may be counted when a pairing involves sources both of which are no more attractive than the buffer; such cases provide little information about relative attractiveness but do provide independent confirmation of the validity of the assay (5). Tests of preference transitivity and consistency among replicates are available by analysis of deviance (equivalent to likelihood ratio testing). Maximum likelihood estimates of the relative attractiveness coefficients $a i$, reported with their standard errors, are denoted throughout by $A i$, or simply $A$ in a listing where index $i$ is understood.

Studies with plant species and cultivars. All assays were conducted with five to seven replicate plates for each pairing of sources. Unless otherwise mentioned, each assay was repeated three times. P11 = an assay with all possible pairings among four source solutions; root exudates from mustard and rape together with ORE and buffer. $\mathrm{Pl} 2$ = an assay with all possible pairings among four source solutions; root exudates from oats and wheat together with ORE and buffer. $\mathrm{Pl} 3$ = an assay with four source solutions; root exudates from canary grass and Arabidopsis sp. together with ORE and buffer, in all possible pairings except Arabidopsis sp. with canary grass. $\mathrm{Pl} 4=$ all possible pairings among four source solutions; root exudates from clover and tomato together with ORE and buffer, three like-with-like pairings, clover with clover, tomato with tomato, and ORE with ORE, and the pairing of buffer with distilled water, were assayed together. $\mathrm{Pl5}=$ six source solutions; root exudates from three onion cultivars (Granex Hybrid, Texas 502, and Evergreen Long White Bunching) and two leek cultivars (Broad London and Large American Flag), together with $0.05 \mathrm{M} \mathrm{CaCl}_{2}$ solution as a buffer solution were each paired with ORE in one assay. This combination was conducted twice.

Studies with ORE. Except for the first, which is fundamental to any quantitative bioassay, the next series of assays were performed to characterize the physical and chemical properties of
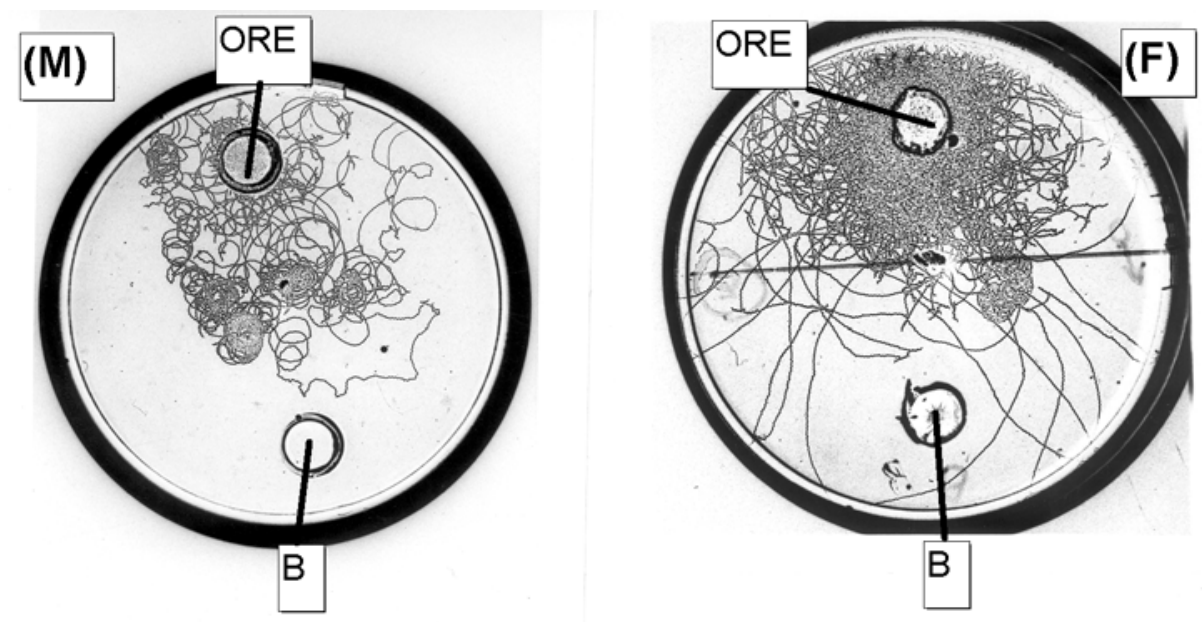

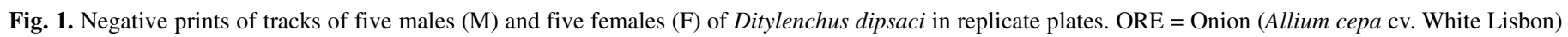
root exudates. $\mathrm{B}=0.05 \mathrm{M} \mathrm{CaCl}_{2}$ buffer. 
the attractive component in ORE; all were conducted with five replicate plates per pairing of source solutions. Re1 = five source solutions; four 10-fold serial dilutions (with buffer) of ORE and undiluted ORE, were each paired with buffer in one assay. $\operatorname{Re} 2=$ an assay with four source solutions; ORE heated to the boiling point and ORE autoclaved at $120^{\circ} \mathrm{C}$ for $15 \mathrm{~min}$, together with buffer and ORE, in all possible pairings except for boiled ORE with autoclaved ORE. This combination was conducted twice. $\operatorname{Re} 3$ = an assay with all possible pairings of three solutions; ORE, dialyzed ORE, and buffer. ORE ( $2 \mathrm{ml}$ ) was dialyzed against water for $24 \mathrm{~h}$ at $4^{\circ} \mathrm{C}$ using a Spectre/Por membrane (molecular weight [MW] cutoff $=3,500 \mathrm{kDa}$ ) with five 2-liter dialysate replacements. $\operatorname{Re} 4=$ for column separation, $4.5 \mathrm{~g}$ of Sephadex G-10 (Pharmacia, Israel) was boiled with 20-ml distilled water for $60 \mathrm{~min}, 1 \mathrm{ml}$ ORE was passed through a $10-\mathrm{ml}$ column in a $1.5 \times$ $8 \mathrm{~cm}$ tube. Retained lower MW components $(<700 \mathrm{kDa})$ were eluted with $2 \times 2 \mathrm{ml}$ distilled water. Two such columns provided four fractions, $>$ MW $700 \mathrm{kDa}$ and $<\mathrm{MW} 700 \mathrm{kDa}$ from each of columns a and b; each was paired with ORE in one assay. All solutions were brought to the same base dilution (1 in 5).

Host penetration study. Clover, tomato and 'White Lisbon' onion seeds were germinated in $0.8 \%$ Delrite for 2, 5 and 8 days respectively, the different times being necessary to standardize root lengths initially. Three plantlets, one from each source, were equally spaced around a 5-cm-diameter petri plate with the same agar film as in routine bioassays, and a drop of the same nematode suspension (280 to 300 species) was placed at the center, $3 \mathrm{~cm}$ distant from each plantlet. Seedlings were harvested after incubation at $20^{\circ} \mathrm{C}$ for $24,48,72$, and $96 \mathrm{~h}$ with five replicate plates each time. Invasive nematodes in roots were counted after staining with acid-fuchsin lactophenol.

Nematode attraction assays in soil medium. In this set of experiments, we evaluated the migration rates in soil medium of axenic or field population of $D$. dipsaci. Assays consisted of a pair-choice test conducted at room temperature $\left(22\right.$ to $\left.25^{\circ} \mathrm{C}\right)$ in a 9-cm-diameter petri plate containing $30 \mathrm{~g}$ of quartz sandy soil, with a particle size as much as $0.2 \mathrm{~mm}$., moisturized by tap water up to field capacity $(6.75 \mathrm{ml}$ of water per $18.75 \mathrm{ml}$ of soil), spread into a flat plane. Two sources, solutions of exudates (or three 10fold serial dilutions [with buffer] of ORE) or controls, are spotted on the soil, $3.5 \mathrm{~cm}$ symmetrically from the center on the same

TABLE 1. Estimated relative attractiveness coefficients for root exudates from representatives of several plant species in bioassays with Ditylenchus dipsaci

\begin{tabular}{lccc}
\hline \multirow{2}{*}{$\begin{array}{l}\text { Assay code and } \\
\text { exudate source }\end{array}$} & \multicolumn{3}{c}{ Relative attractiveness $(A i \pm$ SE) } \\
\cline { 2 - 3 } After $30 \mathrm{~min}$ & After $60 \mathrm{~min}$ & After $120 \mathrm{~min}$ \\
\hline $\begin{array}{l}\text { Assay P11 } \\
\text { Onion root exudates }\end{array}$ & $1.14 \pm 10.13$ & $1.56 \pm 0.12$ & $1.66 \pm 0.12$ \\
(ORE) & & & \\
Mustard & $0.32 \pm 0.17$ & $0.31 \pm 0.14$ & $0.46 \pm 0.14$ \\
Rape & $0.02 \pm 0.18$ & $-0.07 \pm 0.13$ & $0.05 \pm 0.14$ \\
Buffer (control) & 0 & 0 & 0 \\
Assay P12 & & & \\
ORE & $1.65 \pm 0.18$ & $1.71 \pm 0.14$ & $1.89 \pm 0.13$ \\
Oats & $0.96 \pm 0.19$ & $0.85 \pm 0.15$ & $0.61 \pm 0.16$ \\
Wheat & $0.08 \pm 0.18$ & $0.00 \pm 0.15$ & $0.03 \pm 0.12$ \\
Buffer (control) & 0 & 0 & 0 \\
Assay P13 & & & \\
ORE & $1.45 \pm 0.13$ & $1.14 \pm 0.10$ & $0.92 \pm 0.09$ \\
Arabidopsis sp. & $-0.28 \pm 0.13$ & $-0.34 \pm 0.11$ & $0.11 \pm 0.09$ \\
Canary grass & $-0.54 \pm 0.13$ & $-0.51 \pm 0.14$ & $-0.58 \pm 0.14$ \\
Buffer (control) & 0 & 0 & 0 \\
Assay P14 & & & \\
ORE & $2.14 \pm 0.34$ & $2.50 \pm 0.31$ & $2.25 \pm 0.31$ \\
Tomato & $0.80 \pm 0.34$ & $0.57 \pm 0.30$ & $0.37 \pm 0.31$ \\
Clover & $-0.97 \pm 0.43$ & $-0.36 \pm 0.34$ & $-0.56 \pm 0.35$ \\
Water & $-0.98 \pm 0.68$ & $0.04 \pm 0.29$ & $-0.34 \pm 0.41$ \\
Buffer (control) & 0 & 0 & 0 \\
\hline
\end{tabular}

diameter, $0.02 \mathrm{ml}$ per target area. A nematode suspension (usually 300 to 350 species) is placed at the center of the plate and covered. Soil samples $\left(1 \mathrm{~cm}^{3}\right)$ were collected around the two testedsources and the nematodes were counted after $24 \mathrm{~h}$.

One assay consists of several such pairings of sources performed simultaneously with five to seven replicate plates for every pairing.

\section{RESULTS AND DISCUSSION}

In the standard bioassay conditions defined here, all the lifestages of $D$. dipsaci tested (female, male, and juveniles,) can be observed to move quickly (often more than 4 to $5 \mathrm{~cm}$ per h) through the agar film in typical (12) undulating horizontal locomotion. When movement is toward an apparently attractive source target area, after an erratic initial orientation, their course is smoothly curved with little arc at first but increasing arc as the target area is approached. In the neighborhood of the target, some nematodes break their curved path with an outwardly rotating turn into the target, some pass around or through the target before turning, while others pass around and close to the target with no apparent turn. Those nematodes remaining in the vicinity of the target area, where they are counted after 30, 60, or $120 \mathrm{~min}$, are rarely stationary: usually they are moving in approximately circular orbits with occasional changes in radius. Some features of this pattern are visible in Figure 1 which shows tracks of five males (M) and five females (F) over $24 \mathrm{~h}$ in replicate plates of the otherwise standard assay conditions with source pair ORE and $\mathrm{CaCl}_{2}$ buffer. In studies with ORE, elapsed times of $60 \mathrm{~min}$ (occasionally only $30 \mathrm{~min}$ ) are usually ample to obtain repeatable assay results.

TABLE 2. Estimated relative attractiveness coefficients for root exudates from onions (ORE) and leeks in bioassays with Ditylenchus dipsaci

\begin{tabular}{lccc}
\hline \multirow{2}{*}{$\begin{array}{l}\text { Assay code and } \\
\text { exudate source }\end{array}$} & \multicolumn{3}{c}{ Relative attractiveness $(\mathrm{Ai} \pm \mathrm{SE})$} \\
\cline { 3 - 4 } P15 & After $60 \mathrm{~min}$ & After $120 \mathrm{~min}$ & After $180 \mathrm{~min}$ \\
\hline buffer & $-2.28 \pm 0.26$ & $-1.91 \pm 0.21$ & $-1.56 \pm 0.18$ \\
'Broad London' & $-0.10 \pm 0.13$ & $-0.80 \pm 0.15$ & $-0.90 \pm 0.16$ \\
'Large American Flag', & $-0.47 \pm 0.13$ & $-0.39 \pm 0.12$ & $-0.80 \pm 0.13$ \\
'Long White Bunching' & $-0.62 \pm 0.13$ & $-0.71 \pm 0.14$ & $-0.79 \pm 0.15$ \\
'Granex Hybrid' & $0.02 \pm 0.13$ & $0.36 \pm 0.13$ & $0.22 \pm 0.15$ \\
'Texas Grano 502' & $0.14 \pm 0.12$ & $-0.04 \pm 0.11$ & $0.00 \pm 0.12$ \\
'White Lisbon' & 0 & 0 & 0 \\
ORE (control) & & & \\
P15 repeated & & & \\
buffer & $-3.51 \pm 0.38$ & $-2.41 \pm 0.22$ & $-2.49 \pm 0.23$ \\
'Broad London' & $-0.54 \pm 0.13$ & $-0.53 \pm 0.13$ & $-0.85 \pm 0.15$ \\
'Large American Flag', & $-0.01 \pm 0.12$ & $-0.17 \pm 0.11$ & $-0.15 \pm 0.13$ \\
'Long White Bunching & $-0.45 \pm 0.14$ & $-0.52 \pm 0.14$ & $-0.66 \pm 0.14$ \\
'Granex Hybrid' & $-0.21 \pm 0.13$ & $0.13 \pm 0.13$ & $-0.09 \pm 0.12$ \\
'Texas Grano 502' & $0.22 \pm 0.13$ & $0.28 \pm 0.13$ & $0.05 \pm 0.13$ \\
'White Lisbon'ORE & 0 & 0 & 0 \\
(control) & & & \\
P15 supplement & & & \\
buffer & $-4.41 \pm 0.69$ & $-3.80 \pm 0.50$ & $-3.50 \pm 0.45$ \\
'Large American Flag' & $-0.12 \pm 0.12$ & $-0.03 \pm 0.13$ & $-0.16 \pm 0.12$ \\
'White Lisbon' & 0 & 0 & 0 \\
ORE (control) & & & \\
\hline
\end{tabular}

TABLE 3. Penetration preferences expressed by Ditydenchus dipsaci. Mean counts of nematodes per onion root length $( \pm \mathrm{SE})$

\begin{tabular}{lccr}
\hline & \multicolumn{3}{c}{ Plantlet type } \\
\cline { 2 - 4 } Elapsed time $(\mathrm{h})$ & Onion & Tomato & \multicolumn{1}{c}{ Clover } \\
\hline 24 & $57.2 \pm 10.5$ & $18.2 \pm 3.5$ & $11.4 \pm 3.5$ \\
48 & $96.8 \pm 10.5$ & $17.9 \pm 2.6$ & $12.3 \pm 3.5$ \\
72 & $78.2 \pm 10.5$ & $9.8 \pm 1.7$ & $3.3 \pm 2.1$ \\
96 & $86.4 \pm 10.5$ & $8.1 \pm 1.7$ & $3.9 \pm 2.1$ \\
\hline
\end{tabular}




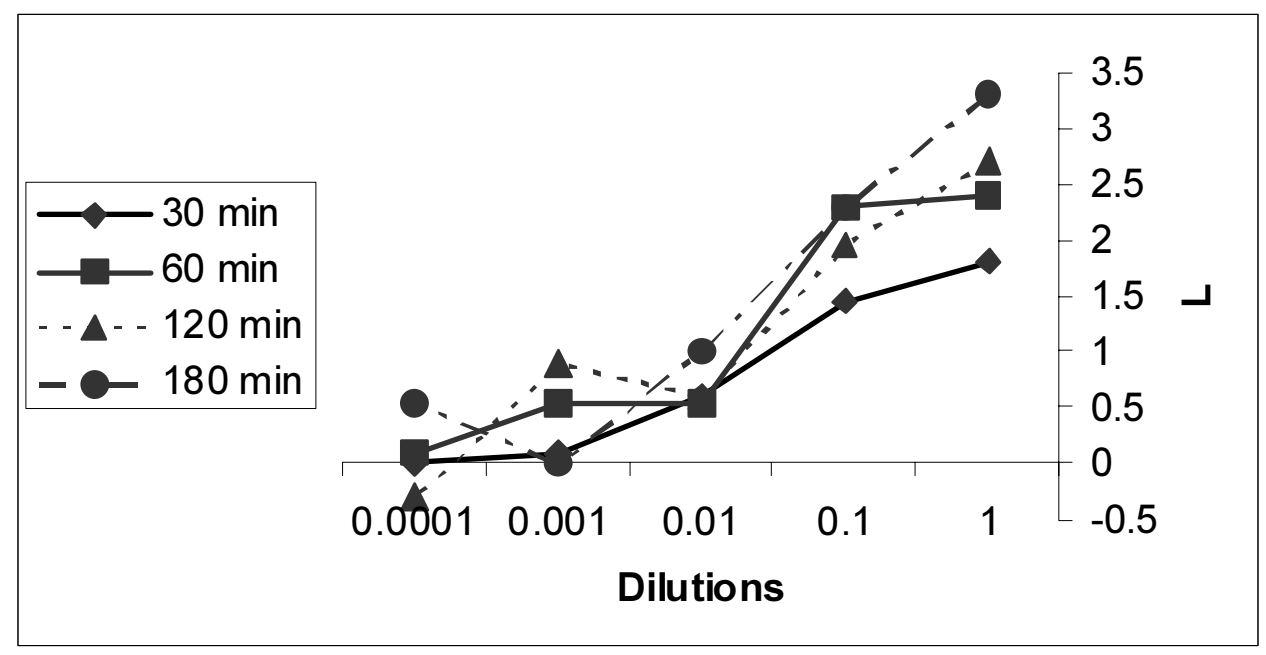

Fig. 2. Plot of relative attractiveness coefficients (L) against dilution exponent. Assays performed in agar medium using axenic Ditylenchus dipsaci culture.

TABLE 4. Estimated relative attractiveness coefficients for treated onion root exudates (ORE) in bioassays with Ditylenchus dipsaci

\begin{tabular}{lccc}
\hline \multirow{2}{*}{$\begin{array}{l}\text { Assay code and } \\
\text { source }\end{array}$} & \multicolumn{2}{c}{ Relative attractiveness $(\mathrm{Ai} \pm \mathrm{SE})$} \\
\cline { 2 - 4 } Re2 & After $30 \mathrm{~min}$ & After $60 \mathrm{~min}$ & After $120 \mathrm{~min}$ \\
ORE & $2.08 \pm 0.26$ & $2.89 \pm 0.19$ & $2.62 \pm 0.17$ \\
Boiled ORE & $1.88 \pm 0.26$ & $2.91 \pm 0.20$ & $2.52 \pm 0.18$ \\
Autoclaved ORE & $1.99 \pm 0.29$ & $2.64 \pm 0.22$ & $2.37 \pm 0.19$ \\
Buffer (control) & 0 & 0 & 0 \\
Re2 repeated & & & \\
ORE & $1.38 \pm 0.10$ & $2.64 \pm 0.10$ & $2.83 \pm 0.11$ \\
Boiled ORE & $1.35 \pm 0.11$ & $2.63 \pm 0.10$ & $2.72 \pm 0.12$ \\
Autoclaved ORE & $1.13 \pm 0.11$ & $2.49 \pm 0.10$ & $2.64 \pm 0.12$ \\
Buffer (control) & 0 & 0 & 0 \\
\hline
\end{tabular}

In all of these studies the preference transitivity hypothesis was tested (with Type I error rate set at 0.01) whenever the assay design permitted. It was never rejected and so interpretation in terms of the relative attractiveness coefficients $a i$ is possible throughout: in a pairing of sources $i$ and $j$, a difference $(a i-a j)$ equal to 0.0 corresponds to $p i j=0.5,(a i-a j)=1.0$ corresponds to $p i j=0.734$ and $(a i-a j)=2.0$ to $p i j=0.881$; if $a i<a j$, then $(a j-a i)$ is interpreted similarly in terms of $p j i=(1-p i j)$.

Estimated relative attractiveness coefficients obtained from the four assays (P11 to P14), performed with axenic nematodes culture, with root exudates from representatives of different plant species are listed in Table 1. Field population revealed the same results (data not shown). ORE is consistently much more attractive than the buffer control in all the assays. The only other detectable effects in Table 1 are for oat cv. Lodi and mustard cv. Albatros (exudates from both are more attractive than buffer but less attractive than ORE) and canary grass exudates which are less attractive than buffer and, therefore, are classified as repellent. We do not know if the attraction to oats and mustard cues is the same as that for ORE, or if the attractive components are less concentrated in these exudates preparations, or if quite different exudates properties are involved. The finding that canary grass exudates are repellent indicates that semiochemicals contribute to the expression of the known host preferences of this population of $D$. dipsaci, as it infects onion but not canary grass.

The possibility that attractiveness of onion root exudates might be specific to the White Lisbon cultivar, used throughout as the ORE source, is examined in Table 2 (with $A=$ zero for ORE 'White Lisbon' as a positive control) compiled from assay P15 and its repetition. Exudates from all onion and leek cultivars tested are more attractive than the buffer. No differences in rela-
TABLE 5. Estimated relative attractiveness coefficients for dialyzed onion root exudates (ORE) in bioassays with Ditylenchus dipsaci (assay Re3)

\begin{tabular}{lcc}
\hline & \multicolumn{2}{c}{ Relative attractiveness $(A i \pm \mathrm{SE})$} \\
\cline { 2 - 3 } Source & After $30 \mathrm{~min}$ & After $60 \mathrm{~min}$ \\
\hline Buffer & $-2.46 \pm 0.26$ & $-3.01 \pm 0.34$ \\
Dialyzed ORE & $-2.00 \pm 0.23$ & $-3.69 \pm 0.51$ \\
ORE (control) & 0 & 0 \\
\hline
\end{tabular}

tive attractiveness are detected among exudates from 'Texas Grano 502', 'Granex Hybrid' and 'White Lisbon'; these three cultivars are "dry" onions, but there is no evidence yet, that they share the same basis of attractiveness to D. dipsaci. In contrast, exudates from the "scallion" type ('Evergreen Long White Bunching') and from one of the leeks ('Broad London') are significantly less attractive than ORE. The only results not consistent with this pattern of grouping attractiveness by onion types are those for exudates from the leek, 'Large American Flag', which was significantly less attractive than ORE in the original assay but not in the repetition. Exudate solution from this leek cultivar and the buffer solution were each paired with ORE (five replicate plates per pair) in a supplementary assay with results in the bottom panel of Table 2. Both exudates solutions are more attractive than the buffer but no significant difference in relative attractiveness between them is detected.

The host penetration study was performed to correlate relative attractiveness of root exudates, as estimated in the bioassays, with preferential root invasion by the same nematode population under the same assay conditions. Although root lengths of clover, tomato, and onion plantlets were standardized initially, differences in growth rates produced root lengths in the ratio $3: 3: 1$ by the time of the $24 \mathrm{~h}$ penetration count, 3:4:1 at the $48 \mathrm{~h}$ count, and 5:6:1 at the 72 and $96 \mathrm{~h}$ counts. Mean counts in Table 3 have been adjusted to a "per onion root length" basis. According to this measure, penetration preferences follow the same pattern as those predicted by relative attractiveness coefficients in assay P14 (Table 1).

Results from the dilution series assay (Re1) are shown in Figure 2. Relative attractiveness is linear in relation to dilution exponent and therefore log-linear in relation to ORE concentration.

Neither adjusting $\mathrm{pH}$ of the $\mathrm{CaCl}_{2}$ buffer to match that of ORE and vice versa, nor heating ORE in a water bath in increments of $20^{\circ} \mathrm{C}$ up to $100^{\circ} \mathrm{C}$, had any effect on relative attractiveness of ORE (data not shown). Consequences of boiling and autoclaving ORE are shown in Table 4 where there is no evidence of loss of attractiveness associated with these treatments. 
TABLE 6. Estimated relative attractiveness coefficients for column separated fractions of onion root exudates (ORE) in bioassays with Ditylenchus dipsaci (assay Re4)

\begin{tabular}{llc}
\hline & \multicolumn{2}{c}{ Relative attractiveness $(A i \pm \mathrm{SE})$} \\
\cline { 2 - 3 } Source solution & \multicolumn{1}{c}{ After 60 min } & After 120 min \\
\hline Buffer & $-1.78 \pm 0.17$ & $-1.21 \pm 0.15$ \\
>MW 700 kDa column a & $-1.06 \pm 15$ & $-1.36 \pm 0.19$ \\
>MW 700 kDa column b & $-1.23 \pm 0.14$ & $-1.18 \pm 0.15$ \\
<MW 700 kDa column a & $-0.07 \pm 0.12$ & $-0.02 \pm 0.13$ \\
<MW 700 kDa column b & $-0.06 \pm 0.09$ & $-0.13 \pm 0.11$ \\
ORE (control) & 0 & 0 \\
\hline
\end{tabular}

Assays were performed with two proteolytic digestions of ORE: lyophilized ORE incubated with proteinase K (from Tritirachium album, Boehringer Mannheim, Germany) or protease type XIV (from Streptomyces griseus, Sigma, Israel). In both cases there was no loss in relative attractiveness when compared with lyophilized and standard ORE (data not shown).

Results from dialysis of ORE (assay Re3) are listed in Table 5: there is no detectable difference in relative attractiveness between dialyzed ORE and buffer, which indicates a MW $<3,500 \mathrm{kDa}$ for the attractive component in ORE. Results from the repetition (not shown) of assay Re4 were very similar to those in Table 6 and yield identically the same inference: relative attractiveness of fractions with $\mathrm{MW}>700 \mathrm{kDa}$ are close to that of buffer while relative attractiveness of fractions with $\mathrm{MW}<700 \mathrm{kDa}$ are not detectably different from that of ORE.

The ability to attract nematodes under soft and smooth media texture, which allows an easy migration of both the attractant (ORE) and the responding nematodes, was evaluated by using the agar media. In nature, however, solid matrix like soil may reduce the efficiency of the attractant diffusion and the capacity of the nematodes to migrate effectively. Results from the dilution series assay in sandy soil media are shown in Figure 3. Relative attractiveness is linear in relation to dilution exponent and therefore log-linear in relation to ORE concentration. These results reveal at least two important conclusions: (i) nematodes attraction assay in agar serves as a good model for chemo attraction in solid matrix like sandy soil. (ii) field population behaves and responds to chemo attraction source in solid medium much the same as axenic nematode culture.

We have demonstrated that axenic and field populations of $D$. dipsaci juveniles recognizes a chemo attractive component of dry onion root exudates in a reliable quantitative bioassay and that this behavior corresponds to their root penetration preferences under the same conditions and with their known host preference under field conditions. It remains to consider our preliminary characterization of the chemo attractant from ORE in relation to the array of chemical possibilities. In the convolution of rhizophagous nematodes and their hosts there is an obvious advantage to nematodes if chemo attraction involves metabolic products that hosts cannot avoid exuding.

Root exudates can be classified broadly according to their rates of diffusion in soil. First are the volatile or gaseous compounds; $\mathrm{CO}_{2}$ in particular is known to be a chemotactic compound for several phytonematodes $(4,10,14)$. Assay $\operatorname{Re} 2$ establishes that we are dealing with a nonvolatile component of ORE, and therefore, eliminates these possibilities. Second are the water soluble and high diffusible components including salts, organic and inorganic acids and their derivatives, carbohydrates, and glycoproteins. From this group, hydroxyl and other ions as well as several soluble sugars are reported as chemo tactic for different phytonematodes $(3,18)$. More recently, kairomones have been implicated in host finding by Heterodera avenae juveniles (16), the chemo attractive components being nonvolatile, water soluble with a MW of 500 to $5,000 \mathrm{kDa}$, and probably peptides. Properties of the chemo attractant from ORE are consistent with it

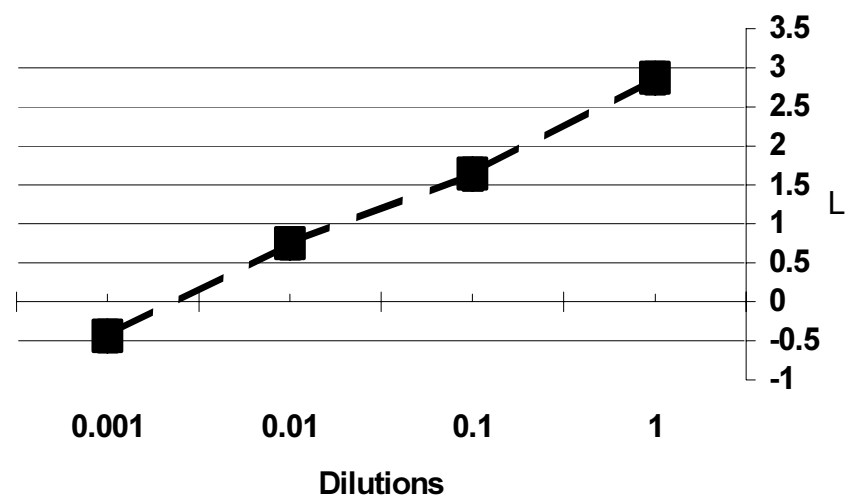

Fig. 3. Plot of relative attractiveness coefficients (L) against dilution exponent. Assays performed in sandy soil medium using field population of ditylenchus dipsaci.

belonging to this group, a small peptide ( 5 to 7 amino acids) being a likely possibility. The third group consists of nondiffusible materials, especially those released from root apices, including sloughed root caps and mucilages (20).

\section{ACKNOWLEDGMENTS}

The research was supported by a grant from the Chief Scientist of the Israeli Ministry of Agriculture and Rural Development, and an International Travel Grant from the South Carolina Agricultural Experiment Station. This manuscript is dedicated to the memory of the late Professor Peter Burrows, our dear colleague and friend.

\section{LITERATURE CITED}

1. Abou-Setta, M. M., and Duncan, L. W. 1998. Attraction of Tylenchulus semipenetrans and Meloidogyne javanica to salts in vitro. Nematropica 28:49-59.

2. Aftalion, B., and Cohn, E. 1990. Characterization of two races of the stem and bulb nematode Ditylenchus dipsaci in Israel. Phytoparasitica 18:229-232.

3. Bird, A. F. 1959. The attractiveness of roots to the plant parasitic nematodes Meloidogyne javanica and M. hapla. Nematologica 4:322335.

4. Bird, A. F. 1960. Additional notes on the attractiveness of roots to plant parasitic nematodes. Nematologica 5:217.

5. Burrows, P. M., Barnett, O. W., and Zimmerman, M. T. 1983. Color attraction and perception in Macrosiphon euphorbae. Can. J. Zool. 61:202-210.

6. Castro, C. E., Belser, N. O., McKinney, H. E., and Thomason, I. J. 1989. Quantitative bioassay for chemotaxis with plant parasitic nematodes. J. Chem. Ecol. 15:1297-1309.

7. Clemens, C. D., Aumann, J., Spiegel, Y., and Wyss, U. 1994. Attractantmediated behavior of mobile stages of Heterodera schachtii. Fundam. Appl. Nematol. 17:569-574.

8. Colgan, P. W., and Smith, J. T. 1985. Experimental analysis of food preference transitivity in fish. Biometrics 41:227-236.

9. Diez, J. A., and Dusenbery, D. B. 1989. Repellent of root-knot nematodes from exudate of host roots. J. Chem. Ecol. 15:2445-2455.

10. Dusenbery, D. B. 1987. Prospects for exploiting sensory stimuli in nematode control. Chapter 19 in: Vistas on Nematology, J. A. Veech, and D. W. Dickson, eds. Society of Nematologists, Hyattsville, MD.

11. Grundler, F., Schnibbe, L., and Wyss, U. 1991. In vitro studies on the behavior of second stage juveniles of Heterodera schachtii (Nematoda: Heteroderidae) in response to host plant root exudates. Parasitology 103:149-155.

12. Gubina, V. G. 1982. Nematodes of Plants and Soils: Genus Ditylenchus. The Academy of Sciences of the USSR Helminthological Laboratory. Geti Saad, trans. Translated from Russian. Published in 1985 for the OICD, ARS, United States Department of Agriculture.

13. Hale, M. G., Moore, L. D., and Griffin, G. J. 1987. Root exudates and exudation. Pages 163-203 in: Interactions Between Non-pathogenic Soil Microorganisms and Plants. Y. R. Dommergues, and S. V. Krupa, eds. Elsevier, Amsterdam.

14. Klingler, J. 1965. On the orientation of plant nematodes and of some other soil animals. Nematologica 11:4-18. 
15. Le Saux, R., and Queneherve, P. 2002. Differential chemotactic responses of two plant-parasitic nematodes, Meloidogyne incognita and Rotylenchulus reniformis, to some inorganic ions. Nematology 4:99-105.

16. Moltmann, E. 1990. Kairomones in root exudates of cereals. Their importance in host finding of juveniles of the cereal cyst nematode Heterodera avenae (Woll.), and their characterization. J. Plant Dis. Prot. 97:458-469.

17. Perry, R. N., and Aumann, J. 1998. Behaviour and sensory responses. Pages 75-101 in: The Physiology and Biochemistry of Free-living and Plant Parasitic Nematodes. R. N. Perry and D. J. Wright, eds. CAB International, London.

18. Prot, J.-C. 1980. Migration of plant parasitic nematodes toward plant roots. Rev. Nematol. 3:305-318

19. Rolfe, R. N., Barrett, J. and Perry, R. N. 2000. Analysis of chemosensory responses of second stage juveniles of Globodera rostochiensis using electrophysiological techniques. Nematology 2:523-533.

20. Rovira, A. D. 1973. Zones of exudation along plant roots and spatial distribution of microorganisms in the rhizosphere. Pestic. Sci. 4:361-366.

21. s'Jacob, J. J., and Benzoijen, J. V. 1977. A Manual for Practical Work in Nematology. Agric. Univ., Wageningen, the Netherlands.

22. Wubben, M. J. E., Su, H., Rodermel, S. R., and Baum, T. J. 2001. Susceptibility of the sugar beet cyst nematode is modulated by ethylene sinal transduction in Arabidopsis thaliana. Mol. Plant-Microbe Interact. $14: 1206-1212$

23. Zhao-Xiao, W., Schmitt, M., Hawes, M. C., and Zhao, X. W. 2000. Species-dependent effects of border cell and root tip exudates on nematode behavior. Phytopathology 90:1239-1245.

24. Zuckerman, B. M., and Jansson, H.-B. 1984. Nematode chemotaxis and possible mechanisms of host/prey recognition. Ann. Rev. Phytopathol. 22:95-113 